\title{
Lessons of pandemic: the return to a sustainable rural economy
}

\section{Editorial}

In most countries around the world, after the COVID-19 pandemic, a series of measures were developed that, in one way or another, affected the production chains and employment in a series of goods and services, all intending to avoid close contacts between people and reduce the likelihood of infection.

The economic dynamics that have been shown and are generally expected in various countries, after the measures taken, follow behavior in the shape of a V or a similar figure. In the specific case of Peru, from a pre-pandemic level of 100 in the value of production registered in the fourth quarter of 2019, it went to a value of 69 in the second quarter of 2020. In the third quarter, recovery has been already shown with a level of 89 , and in the fourth quarter, a level of 93 is expected. ${ }^{1}$

It should be noted, however, that after the declaration of national emergency, lockdown, and other actions taken in Peru since March 15,2020 , measures that were recognized internationally, and that played a role of containment in the first few weeks, Peru ranks first in deaths per 100,000 inhabitants over the world, followed by Belgium, Bolivia, and Brazil, among others.

We must add that, according to the BCRP (2020), it is estimated that this year, Peru would have one of the greatest drops in its domestic production $(-12.7 \%)$. This drop is one of the highest not only in Latin America but also in the world, this is greater than the one expected for Argentina (-11.3\%) or the one expected for the United Kingdom $(-10.4 \%)$ or India $(-10.2 \%)$.

However, not everything has neither been and nor will be negative, there is also good news. First, everything indicates that the recovery of domestic economic activity will not wait long, in particular, since it is a crisis caused by a supply closing shock, as it gradually releases, it could reach previous levels faster; although demand or spending has suffered and could delay recovery, this situation may be alleviated with the arrival of the vaccine. In this perspective, according to the same source, the internal production of Peru would grow by $11 \%$ in 2021, reaching pre-pandemic levels in 2022.

Another remarkable aspect is that, if we look at the behavior of economic activity in Peru in the first half of 2020, we find that the Primary GDP (-12.2\%) falls less than the non-Primary GDP (-18.9\%). Moreover, when disaggregating, we find that the only sector that registers positive growth is the Agricultural sector (2.1\%).

This must be a stylized fact that should have been recorded in most economies worldwide and the truth is that there cannot be a conflict between food and health. Let us remember in turn that food products are closely related to the natural environment or the resources of water, land, pastures, forests, animals, etc.; precisely the pandemic and the lockdown measures that have taken place on a global scale, have caused a positive externality in the environment, which has made it possible to observe a regrowth of natural resources, specifically flora and fauna in various parts of the planet.

Besides these important facts, there is another linked to

\author{
Volume 5 Issue I - 202 I
}

\author{
Angel Francisco Polo Campos \\ Facultad de Ciencias Económicas, Universidad Nacional de \\ Trujillo, Av. Juan Pablo II s/n - Ciudad Universitaria,Trujillo, Perú \\ Correspondence: Angel Francisco Polo Campos, Facultad de \\ Ciencias Económicas, Universidad Nacional de Trujillo, Av. Juan \\ Pablo II s/n - Ciudad Universitaria,Trujillo, Perú, \\ Email a-polocampos@hotmal.com
}

Received: October 04, 2020 | Published: February 02, 202 I

employment. According to the National Household Survey- ENAHO 2020 , in Peru the employed population in the second quarter, decreased by $37.7 \%$ compared to the same period of 2019 ; however, as can be seen in Figure 1, which shows the evolution of sectoral employment in the first and second quarters of 2020, in four of the five sectors, the employment dynamics corresponds to the first segment of the $\mathrm{V}$, that is, there is a sharp drop in employment levels, with construction and manufacturing being the most affected. However, only the employment curve in the extractive activities Agriculture, Fishing and Mining reflects a dynamic that corresponds to the second segment of the $\mathrm{V}$, that is, employment grew $15.8 \%$ respect to the same quarter of the previous year, which in turn it is equivalent to an increase in the mass of income ${ }^{1}$.

Disaggregating, even more, it is observed that, within these three branches of extractive activity, agriculture ${ }^{2}$ was the only one that registered growth in employment, mitigating the falls in fishing and mining. Agriculture in rural areas added more than 800 thousand new jobs during the health crisis, even though it is a sector with the highest levels of poverty.

From the evidence shown, it is clear that the pandemic is teaching us a lesson: an international and national public policy is necessary to value the rural economy, especially in developing countries such as Peru, we must remember that population flows in recent decades go from rural to urban, generating high levels of informality and chaos in cities. It is time to at least stop this trend, history teaches us that the culture of the Incas developed a sustainable rural economy in the mountains, they left us practical lessons of the approach of sowing and harvesting water, through infiltration ditch systems, systems of water conduction channels for irrigation and human consumption, platform system, afforestation around water mirrors, in summary, the integral management of water in a micro-basin or basin. The sustainability of

${ }^{1}$ This fact is good news given that, according to the latest survey applied by IPSOS APOYO (Gestion newspaper of September 28), 78\% of Peruvian households have experienced a reduction in their income.

${ }^{2}$ Also adding animal husbandry and forestry. 
the cities located in the lower parts of the basin, in countries such as Peru, depends, to a great extent, on the management of water in the upper parts of the valleys, that is, on whether the rural or mountain economy is managed sustainably (Figure 1$)^{2}{ }^{2}$

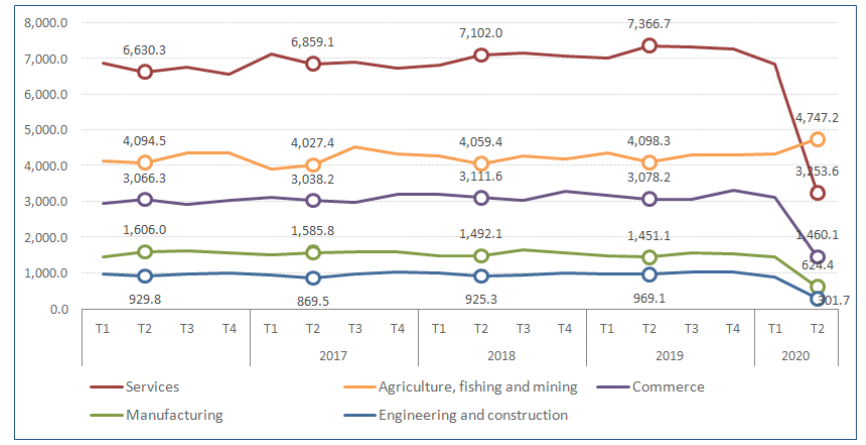

Figure I Evolution of sectoral employment in Peru (thousands of people).

\section{Acknowledgments}

None.

\section{Conflicts of interest}

Authors declare no conflict of interest exists.

\section{References}

1. BCRP. Reporte de inflación. Panorama actual y proyecciones macroeconómicas Lima, Perú. 2021.

2. INEI -Encuesta nacional de hogares. ENAHO Trimestral. Lima, Perú. 2020 . 